$\underline{\text { Review Articles }}$

\title{
Autologous Stem Cell Transplantation for Aggressive Lymphomas
}

Giuseppe Visani ${ }^{1}$, Paola Picardi ${ }^{1}$, Patrizia Tosi ${ }^{2}$, Roberta Gonella ${ }^{3}$,Federica Loscocco ${ }^{1}$, Teresa Ricciardi ${ }^{1}$, Lara Malerba $^{1}$, Barbara Guiducci ${ }^{1}$, Simona Tomassetti ${ }^{2}$, Sara Barulli ${ }^{1}$ and Alessandro Isidori ${ }^{1}$.

${ }^{1}$ Hematology and Stem Cell Transplant Center, AORMN, Pesaro, Italy;

${ }^{2}$ Hematology Unit, Department of Oncology and Hematology, Infermi Hospital, Rimini, Italy

${ }^{3}$ Internal Medicine Unit, AUO San Martino, Genova, Italy

Correspondence to: Giuseppe Visani, MD. Hematology and Hematopoietic Stem Cell Transplant Center, AORMN. Via Lombroso, 61100 Pesaro-Italy. Tel: +39-0721 364039, E-mail: g.visani@ospedalesansalvatore.it or to: Alessandro Isidori, MD, PhD, Hematology and Hematopoietic Stem Cell Transplant Center, AORMN. Via Lombroso, 61100 Pesaro-Italy. Tel: +39-0721 364022E-mail: aisidori@gmail.com

Competing interests: The authors have declared that no competing interests exist.

Published: November 7, 2012

Received: October 22, 2012

Accepted: October 23, 2012

Citation: Mediterr J Hematol Infect Dis 2012, 4(1): e2012075, DOI: 10.4084/MJHID.2012.075

This article is available from: http://www.mjhid.org/article/view/11145

This is an Open Access article distributed under the terms of the Creative Commons Attribution License (http://creativecommons.org/licenses/by/2.0), which permits unrestricted use, distribution, and reproduction in any medium, provided the original work is properly cited.

Abstract. The role of high-dose therapy (HDT) followed by autologous stem cell transplantation (ASCT) in the treatment armamentarium of aggressive B- and T-cell non-Hodgkin lymphoma (NHL) is still a matter of debate. In the pre-Rituximab era, the PARMA study demonstrated the superiority of HDT/ASCT over conventional salvage chemotherapy in chemosensitive, relapsed patients. Subsequently, HDT/ASCT has become a standard approach for relapsed NHL. With the advent of Rituximab in the landscape of NHL, transplantation as part of first-line therapy has been challenged. However, no benefit in terms of disease-free or overall survival of HDT/ASCT over standard therapy was shown when Rituximab was added to both arms. Moreover, the superiority of HDT/ASCT over conventional salvage therapy in patients relapsing from first-line therapy including Rituximab was not confirmed. From these disappointing results, novel strategies, which can enhance the anti-lymphoma effect, at the same time reducing toxicity have been developed, with the aim of improving the outcome of HDT/ASCT in aggressive NHL.

In T-cell lymphoma, few publications demonstrated that consolidation of complete remission with HDT/ASCT is safe and feasible. However, up to one-third of patients may never receive transplant, mostly due to progressive disease, and relapse still remains a major concern even after transplant.

Introduction. Aggressive lymphomas comprise a variety of lymphoid malignancies which can benefit in various phases of the diseases from high-dose therapy (HDT) followed by autologous stem cell transplant (ASCT). Despite data suggesting that prolonged eventfree survival can be achieved with SCT combined with
HDC, there are problems that may limit the utility of this approach for a broad patient population. Moreover, the development of Rituximab has generated a sort of skepticism on the usefulness of HDT/ASCT, especially in front-line therapy. Consequently, there is an urgent need for other effective and well-tolerated approaches 
that will eradicate the residual disease that may persist before ASCT, thus improving outcomes for patients with this life-threatening disease. In addition, approaches with better safety profiles would allow older patients to benefit from this therapeutic option.

In this review, we will deeply discuss the data available about HDT followed by ASCT in aggressive lymphomas.

High-Dose Therapy and Auto-SCT as Part of FirstLine Therapy. On the first decade of study into autologous transplantation for the treatment of aggressive lymphoma, the focus was on the use of this approach to rescue patients after relapse or if the disease already progressed under standard chemotherapy. These encouraging results in relapsed or progressive lymphoma led to the testing of the technique as a primary therapy for the disease.

Thirteen prospective multicenter randomized studies have tried to evaluate the impact of HDT with ASCT as part of the first-line treatment for patients with diffuse large B cell lymphoma (DLBCL) (Table 1) ${ }^{1-12}$ In these trials, patients received initial induction with conventional dose chemotherapy and were then randomly assigned to consolidation with ASCT or additional doses of conventional chemotherapy. However, the results of prospective randomized trials are contradictory, with nine studies showing no difference in outcomes. On the other hand, 4 studies showed improvement in disease-free survival (DFS) and/or overall survival (OS) for the high-dose therapy arm. Of note, several problems have hampered the comparison of data coming from these studies. Inclusion criteria, time of randomization (diagnosis vs after induction therapy), intensity/number of courses of conventional therapy before ASCT, disease status at transplant were varied among different studies, making comparisons difficult. Nonetheless, these trials included different proportions of patients with dissimilar risk categories and different histological subtypes. Last but not least, all these trials were conducted in the pre-rituximab era and thus the results may not be applicable to current practice.

In order to assess the effects of such high-dose treatment on overall survival in patients with aggressive non-Hodgkin lymphoma, the Cochrane Hematological Malignancies Group performed in 2008 a meta-analysis that included data from 15 randomized controlled trials with a total of 3079 patients treated for aggressive NHL. ${ }^{13}$ In general, there was no evidence that HDT improves OS (HR 1.05; CI 0.92 to 1.19) or event free survival (EFS) (HR 0.92; CI 0.80 to 1.05). Nevertheless, in patients with good risk age-adjusted International Prognostic Index (aaIPI) there was some evidence for worse OS (HR 1.46; CI 1.02 to 2.09) when treated with HDT. In contrast, there was suggestive evidence that poor risk patients may benefit from HDT.

Overall, with respect to the large population included in the meta-analysis and the attempts made to

Table 1. Phase III trials of HDT/ASCT in unfavorable non-Hodgkin lymphoma patients

\begin{tabular}{|c|c|c|c|c|c|c|c|c|}
\hline Author & Year & $\begin{array}{c}\text { Patients } \\
\left(\mathbf{n}^{\circ}\right)\end{array}$ & $\begin{array}{c}\text { DLCL } \\
(\%)\end{array}$ & $\begin{array}{l}\text { aaIPI } \\
\geq 2(\%) \\
\end{array}$ & $\begin{array}{c}\text { PFS/EFS } \\
(\%)\end{array}$ & $P$ & OS(\%) & $P$ \\
\hline Gianni [1] & 1997 & 98 & $\begin{array}{l}88 \\
91\end{array}$ & $\begin{array}{l}74 \\
94\end{array}$ & $\begin{array}{l}7 \mathrm{y}: 49 \\
7 \mathrm{y}: 76\end{array}$ & 0.001 & $\begin{array}{l}7 y: 55 \\
7 y: 81\end{array}$ & 0.09 \\
\hline Santini [2] & 1998 & 124 & $\begin{array}{l}72 \\
77\end{array}$ & $\begin{array}{l}59 \\
54\end{array}$ & $\begin{array}{l}6 y: 48 \\
6 y: 60\end{array}$ & N.S. & $\begin{array}{l}6 y: 65 \\
6 y: 65\end{array}$ & N.S. \\
\hline Gisselbrecht [3] & 2002 & 270 & $\begin{array}{c}62.5 \\
60\end{array}$ & $\begin{array}{l}97 \\
99 \\
\end{array}$ & $\begin{array}{l}5 y: 52 \\
5 y: 39\end{array}$ & 0.01 & $\begin{array}{l}5 y: 60 \\
5 y: 46\end{array}$ & 0.007 \\
\hline Kaiser [4] & 2002 & 312 & $\begin{array}{l}61 \\
58 \\
\end{array}$ & $\begin{array}{l}75 \\
73 \\
\end{array}$ & $\begin{array}{l}3 y: 49 \\
3 y: 59\end{array}$ & N.S. & $\begin{array}{l}3 y: 63 \\
3 y: 62\end{array}$ & N.S. \\
\hline Martelli [5] & 2003 & 150 & $\begin{array}{l}84 \\
78\end{array}$ & $\begin{array}{l}100 \\
100\end{array}$ & $\begin{array}{l}5 y: 49 \\
5 y: 61\end{array}$ & N.S. & $\begin{array}{l}5 y: 65 \\
5 y: 64\end{array}$ & N.S. \\
\hline Olivieri [6] & 2005 & 222 & $\begin{array}{l}78 \\
75 \\
\end{array}$ & $\begin{array}{l}68 \\
72 \\
\end{array}$ & $\begin{array}{l}7 y: 44.9 \\
7 y: 40.9\end{array}$ & N.S. & $\begin{array}{l}7 \mathrm{y}: 60 \\
7 \mathrm{y}: 57\end{array}$ & N.S. \\
\hline Vitolo [7] & 2005 & 126 & $\begin{array}{l}90 \\
80 \\
\end{array}$ & $\begin{array}{l}80 \\
87\end{array}$ & $\begin{array}{l}6 y: 48 \\
6 y: 45\end{array}$ & N.S. & $\begin{array}{l}6 y: 63 \\
6 y: 49 \\
\end{array}$ & N.S. \\
\hline Betticher [8] & 2006 & 129 & $\begin{array}{l}69 \\
76\end{array}$ & $\begin{array}{l}88 \\
72\end{array}$ & $\begin{array}{l}3 y: 33 \\
3 y: 39\end{array}$ & N.S. & $\begin{array}{l}3 y: 53 \\
3 y: 46\end{array}$ & N.S. \\
\hline Haioun [9] & 2000 & 451 & $\begin{array}{l}60 \\
55 \\
\end{array}$ & $\begin{array}{l}100 \\
100 \\
\end{array}$ & $\begin{array}{l}8 \mathrm{y}: 55 \\
8 \mathrm{y}: 39 \\
\end{array}$ & 0.02 & $\begin{array}{l}8 \mathrm{y}: 64 \\
8 \mathrm{y}: 49 \\
\end{array}$ & 0.04 \\
\hline Baldisserra [10] & 2006 & 56 & N.R. & $\begin{array}{l}100 \\
100\end{array}$ & $\begin{array}{l}5 \mathrm{y}: 47 \\
5 \mathrm{Y}: 30\end{array}$ & N.S. & $\begin{array}{l}5 y: 47 \\
5 y: 40\end{array}$ & N.S. \\
\hline $\begin{array}{c}\text { Klui-Nelemans } \\
{[11]}\end{array}$ & 2001 & 311 & $\begin{array}{l}50 \\
58 \\
\end{array}$ & $\begin{array}{l}31 \\
29 \\
\end{array}$ & $\begin{array}{l}5 \mathrm{y}: 61 \\
5 \mathrm{y}: 56 \\
\end{array}$ & N.S & $\begin{array}{r}5 y: 68 \\
5 Y: 77 \\
\end{array}$ & N.S. \\
\hline Milpied [12] & 2004 & 197 & $\begin{array}{l}74 \\
76 \\
\end{array}$ & $\begin{array}{l}56 \\
49 \\
\end{array}$ & $\begin{array}{l}5 y: 55 \\
5 y: 37\end{array}$ & 0.037 & $\begin{array}{l}5 y: 74 \\
5 y: 44\end{array}$ & 0.001 \\
\hline
\end{tabular}

Legend. DLCL: diffuse large cell lymphoma, aaIPI: adjusted-age International Prognostic Index, PFS: progression-free survival, EFS: eventfree survival, OS: overall survival, NS: not significant. 
minimize bias, the Authors concluded that there is no evidence for a general benefit of HDT followed by ASCT for patients with aggressive NHL as first-line treatment based on the data available at the time of writing (2008). In fact, the improvements in relapse free survival and complete remission rates did not translate into an overall survival benefit in the respective groups. However, if HDT is employed for high risk patients, there may be a benefit.

With the remarkable increase in the response rate when Rituximab (R) was added to conventional chemotherapy, for new studies comparing standard chemotherapy to HDT followed by SCT with the incorporation of $\mathrm{R}$ into both treatment concepts were required. Several phase II studies and phase III randomized trials investigated the role of HDT followed by ASCT for the initial treatment of DLBCL patients (Table 2). ${ }^{14-20}$

Tarella et a $1{ }^{14}$ performed a prospective multicentre trial to evaluate the combination of rituximab and modified high-dose sequential (HDS) chemotherapy together with multiple peripheral blood progenitor cell (PBPC) support in newly diagnosed DLBCL patients with aaIPI 2-3. In this study, 93 of the 112 patients enrolled completed the planned therapy (5 early and 2 late toxic deaths). Overall, the CR rate was $80 \%$. At a median follow-up of 48 months, the estimated 4-year OS projection was $76 \%$ (CI: $68-85 \%$ ) and the 4-year EFS projection was $73 \%$ (CI: $64-81 \%$ ). No significant differences in OS and EFS were observed between subgroups with germinal-center and activated B-cell phenotype. This study showed the efficacy of combining rituximab and early HDT with multiple PBPC in a subset of DLBCL patients with a dismal prognosis.
Vitolo et al. ${ }^{15}$ incorporated $\mathrm{R}(6$ doses $)$ in a dosedense induction regimen (CEOPx4) coupled with a short intensification phase (MAD x2), followed by HDT (Conditioning: BEAM) and ASCT. Overall, 86\% of the patients completed the treatment, with a CR rate of $82 \%$ (CI: $73-88 \%$ ). With a median follow-up for censored patients of 49 months, the reported 4-year failure-free survival (FFS) rate was $73 \%$ (CI: 63, 5-82, $5 \%$ ) and the 4-year OS rate was $80 \%$ (CI: $71,6-$ $88,4 \%)$.

The GELA group ${ }^{16}$ combined 4 doses of $\mathrm{R}$ with 4 cycles of biweekly ACVBP chemotherapy in 208 highrisk DLBC patients. Responding patients (155 with CR or PR) were than addressed to HDT(BEAM) followed by ASCT. A total of 32 patients did not receive HDT/ASCT. Twenty five were withdrawn during induction therapy, 6 because of insufficient response before consolidation and one because of sudden death. With a median follow-up of 45 months, the 4-year PFS and OS were estimated at 76\% (CI: $69-81 \%$ ) and $78 \%$ (72-83\%).

A case-control study by matching (1:1) patients treated with $\mathrm{R}$ with patients treated with identical chemotherapy (CEOP; ABCVP) program not given $\mathrm{R}$ but submitted to ASCT was also performed in both the Italian and French studies. Regardless of the limitations intrinsic to retrospective analyses, these comparisons demonstrated a marked therapeutic advantage of chemo-immunotherapy over chemotherapy alone in both PFS and OS.

The US/Canadian Intergroup trial (SWOG S9704) ${ }^{17}$ enrolled 370 patients aged $18-65$ years with aaIPI 2 or 3 who received 5 courses of CHOP-21+/- R. Those patients achieving a $\mathrm{CR}$ or PR were randomized to 3 further courses of $\mathrm{CHOP}-21+\mathrm{R}$ or one such course followed by HDT/ASCT. 370 patients started treatment

Table 2. Studies of HDT/ASCT in unfavorable DLBCL patients

\begin{tabular}{|c|c|c|c|c|c|c|c|}
\hline Author & Year & $\begin{array}{c}\text { Patients } \\
\left(\mathrm{n}^{\circ}\right)\end{array}$ & Age & $\begin{array}{c}\text { DLCL } \\
(\%)\end{array}$ & $\begin{array}{c}\text { aaIPI } \geq 2 \\
(\%)\end{array}$ & $\begin{array}{c}\text { PFS/EFS } \\
(\%)\end{array}$ & $\begin{array}{l}\text { OS } \\
(\%) \\
\end{array}$ \\
\hline Tarella [14] & 2007 & 112 & $18-66$ & 79 & 100 & $4 y: 73$ & $4 y: 76$ \\
\hline Vitolo [15] & 2009 & 97 & $19-60$ & 86 & 100 & $4 y: 73$ & $4 y: 80$ \\
\hline Fitoussi [16] & 2011 & 209 & $18-60$ & N.R. & 100 & $4 y: 76$ & $4 y: 78$ \\
\hline Stiff [17] & 2011 & 370 & $18-65$ & 89 & 100 & $2 y: 72$ & N.S. \\
\hline Vitolo [18] & 2011 & 412 & $18-65$ & 100 & 100 & $2 y: 71$ & N.S. \\
\hline Le Gouill [20] & 2011 & 340 & $18-60$ & 100 & N.R. & $3 y: 41$ & N.S. \\
\hline Schmitz [19] & 2011 & 306 & $18-60$ & 100 & 100 & $3 y: 69.8$ & $3 y: 77$ \\
\hline
\end{tabular}

Legend. DLCL: diffuse large cell lymphoma, aaIPI: adjusted-age International Prognostic Index, PFS: progression-free survival, EFS: eventfree survival, OS: overall survival, NS: not significant. 
with $\mathrm{CHOP}(52 \%)$ or R-CHOP (48\%), 128 patients were then randomized to 3 additional courses of (R)CHOP, 125 patients were randomized to 1 more course of (R)-CHOP followed by HDT/ASCT. PFS was significantly better $(\mathrm{p}=0.005)$ after HDT/autoSCT, but OS was not significantly different. The study was not powered, however, to show a difference in PFS (72\% for patients undergoing HDT/ASCT vs. $62 \%$ for patients treated with R-CHOP-21) if the analysis was restricted to patients treated with R-CHOP.

The Italian lymphoma foundation $(\mathrm{FIL})^{18}$ randomized upfront high-risk patients (aaIPI 2 or 3 ) aged 18-65 years with DLBCL or FL grade IIIb to receive 4 courses of R-CHOP-14 or R-(mega)CHOP14 (cyclophosphamide escalated to $1200 \mathrm{mg} / \mathrm{m} 2$ and adriamycin to $70 \mathrm{mg} / \mathrm{m}^{2}$ ). Patients with CR or PR continued treatment as initially randomized with 4 courses of RCHOP-14, 2 courses of R-megaCHOP or R-MAD (mitoxanthrone, cytarabine, dexamethasone) in the absence of response, in all cases followed by BEAM/ASCT. Again, 2-year-PFS was significantly higher for patients receiving HDT/ASCT as compared to R-(mega)CHOP-14 ( $p=0.0128)$, but again OS was not significantly different.

Both the SWOG and the FIL study randomized only patients with chemosensitive disease: patients without $\mathrm{CR}$ or PR after (R)-chemo were not eligible for transplantation. However, while the Italian study indicate that chemosensitive patients may significantly do better with HDT/ASCT with respect to further conventional therapy also when $\mathrm{R}$ is a part of frontline therapy, the results of the SWOG study are not conclusive because the comparison of 8 courses of RCHOP-21 and 5 coursed of R-CHOP-21 followed by HDT/ASCT lacks the statistical power necessary to show significant differences.

The German group ${ }^{19}$ randomized patients between 18 and 60 years with high-risk (IPI 2 or 3) aggressive B-cell lymphoma to receive 8 cycles of CHOE(etoposide)P-14 with $6 \mathrm{R}$ or 4 cycles of MegaCHOEP with escalating doses of cyclophosphamide, etoposide, adriamycin, and prednisolone also administered with $6 \mathrm{R}$. The patients randomized were equally split in the 2 groups. 3 -yearEFS and OS were not significantly different $(p=0.14$ and $p=0.081$, respectively) between the 2 groups.

The GELA ${ }^{20}$ group randomized patients aged 18-60 years with DLBCL in all stages to 4 courses of RCHOP-14 or 2 courses of CEEP (cyclophosphamide, epirubicin, vindesine, and prednisolone) followed by 1 course of MC (methotrexate $3 \mathrm{~g} / \mathrm{m} 2$, cytarabine 100 $\mathrm{mg} / \mathrm{m} 2$ for 5 days) combined with $4 \mathrm{R}$ infusions. Patients were then stratified according to PET scan to receive 3 courses of R-DHAP followed by BEAM/ASCT (PET positive) or experienced a second randomization to either 4 R-CHOP-14 or BEAM/autoSCT (PET-negative). RCHOP-14 was significantly better $(p=0.03)$ than HDT/ASCT in terms of 3-year-EFS in all IPI subgroups including patients with aaIPI 2 or 3 . OS was not significantly different. However, the interpretation of this study is complicated by introducing PET-guided restaging after R-CHOP-14 and use of an alternative chemotherapy (CEEP/MC). Even if this study showed that HDT/ASCT is no better than the combination of $\mathrm{R}$ and $\mathrm{CHO}(\mathrm{E}) \mathrm{P}-14$, this message is restricted to patients who were PETnegative at restaging (chemosensitive patients?) and treatment results in both the conventional and the HDT arm seem surprisingly poor.

In conclusion, results of all these studies incorporating HDT/ASCT in the frontline therapy of aggressive B-cell lymphoma are contradictory and definitive conclusions may indeed not be drawn.

High-Dose Therapy and Auto-SCT for Relapsed Aggressive Lymphoma. The superiority of HDT and ASCT over conventional salvage chemotherapy was demonstrated by Philip et $\mathrm{al}^{21}$ in 1995 in a multicenter, prospective randomized trial for relapsed aggressive non-Hodgkin lymphomas. The Parma trial established HTD/ASCT as the standard therapy in relapsing aggressive NHL patients responding to salvage therapy. This study compared 2 more courses of DHAP chemotherapy to HDT/ASCT in younger patients with relapsed mostly aggressive NHL who initially had responded to 2 cycles of DHAP. Patients who were treated with DHAP followed by HDT/ASCT had significantly better EFS than patients who were treated with salvage chemotherapy alone. The 8-years EFS rate was $36 \%$ in the HDT/ASCT group and $11 \%$ in the conventional treatment group.

Recently, the randomized CORAL study, ${ }^{22}$ performed in the rituximab era, confirmed the results of the PARMA study, reporting a 3-year PFS of $53 \%$ in patients receiving high-dose BEAM therapy after having obtained a response with R-ICE or R-DHAP. The CORAL study randomized younger patients with relapsed or refractory aggressive B-cell lymphoma to 3 courses of either R-DHAP or R-ICE. Results were comparable between the 2 different rituximab containing regimens (R-ICE vs. R-DHAP, CR rate $63.5 \%$ and $62.8 \%$, respectively). However, only $50 \%$ of patients were able to proceed with ASCT. Moreover, in patients relapsing more than 12 months after ASCT, prior rituximab treatment did not affect PFS. Finally chemosensitive patients receiving HDT and ASCT were randomized to maintenance with Rituximab or observation. The final report ${ }^{23}$ confirmed the major findings of first analysis and showed that $R$ 
maintenance did not significantly improve EFS, PFS, or OS.

Due to the results reported from the randomized CORAL study which are less favorable than those reported in non-randomized study, ${ }^{22-23}$ testing effective high dose therapy schedules to increase responses and to reduce both transplant related mortality (TRM) and the incidence of secondary diseases becomes an important area of research in relapsed/refractory lymphomas. ${ }^{24,25}$ Furthermore, there is no evidence, to date, for a superior high-dose therapy regimen in the treatment of refractory or relapsed aggressive lymphomas. In fact, various conditioning regimens have been used as chemotherapy treatment before ASCT, with DFS and OS rates ranging from 34 to $60 \%$ and 26 to $46 \%$, respectively. ${ }^{26-36}$ To date, few randomized trials comparing different conditioning regimens have been performed, and no regimen has demonstrated superiority to another. Furthermore, little is known regarding the comparative toxicity and efficacy of various HDT regimens applied in lymphomas. ${ }^{26-36}$ Advances in the HDT regimens and supportive care have reduced TRM to less than $10 \%$. However, the commonly utilized HDT regimens have lights and shadows, and new strategies with novel drugs have been considered and tested by several Investigators.

Initial studies in relapsed aggressive NHL incorporated total body irradiation (TBI) into the conditioning regimen approach as the mainstay of therapy for chemosensitive NHL. This approach was considered reasonable and effective at the time. Tissue dose limitations, however, prohibit the use of TBI in patients who have received prior consolidative or salvage radiation after initial chemotherapy. More importantly, a significant proportion of the patients treated with ASCT subsequently developed secondary myelodysplasia or acute leukemia. Most transplant centres and groups have moved away from TBIconditioning approaches and have concentrated on chemotherapy-based regimens. ${ }^{35-42}$

Chemotherapy-based regimens consist of 2-4 drug combinations including an alkylating agent given over 6-7 consecutive days. These combination treatments induce CRs in the $60-85 \%$ range while at $2-5$ years after ASCT have resulted in 34-60\% DFS and $24-46 \%$ OS rates. TRM have resulted in $3.8-17 \%$.

Kim JG et $\mathrm{al}^{43}$. have reported the results of a multicenter study aimed to evaluate the efficacy and toxicity of a combination of intravenous busulfan $(\mathrm{Bu})$, cyclophosphamide $(\mathrm{Cy})$ and etoposide $(\mathrm{E})(\mathrm{Bu} / \mathrm{Cy} / \mathrm{E})$ as a conditioning regimen prior to autologous hematopoietic stem cell transplantation in patients with NHL. 64 patients with relapsed/refractory or high risk lymphoma were enrolled. The high-dose chemotherapy consisted of i.v. $\mathrm{Bu}(0.8 \mathrm{mg} / \mathrm{kg}$ for 3 days), Cy (50 $\mathrm{mg} / \mathrm{kg}$ for 2 days) and $\mathrm{E}\left(400 \mathrm{mg} / \mathrm{m}^{2}\right.$ for 2 days). The median age was 43 and DLBCL was the common histological subtype. At a median of follow up of 16.4 months, 15 patients $(23.4 \%)$ exhibited a relapse or progression, while 13 patients $(20.3 \%)$ had died of disease. The estimated 3-year OS and PFS for all patients was 72.1 and $70 \%$, respectively demonstrating the efficacy and tolerability of this conditioning regimen.

Our group ${ }^{44}$ designed an Italian multicenter phase III study to evaluate the safety and the efficacy of increasing doses of bendamustine $\left(160 \mathrm{mg} / \mathrm{m}^{2}, 180\right.$ $\mathrm{mg} / \mathrm{m}^{2}$ and $200 \mathrm{mg} / \mathrm{m}^{2}$ given on days -7 and -6 ) coupled with fixed doses of etoposide, cytarabine and melphalan (BeEAM regimen) for resistant/relapsed lymphoma patients. The basis for testing bendamustine in a novel conditioning regimen arose from preliminary in vitro data on lymphoma cell lines, demonstrating the higher efficacy bendamustine has in combination with etoposide, cytarabine and melphalan with respect to carmustine. 28 NHL patients were enrolled in the study, which also comprises 15 Hodgkin lymphoma patients. In total, 43 patients received a median number of $6 \times 10^{6} \mathrm{CD} 34^{+}$cells $/ \mathrm{kg}$ (range 2.4-15.5). All patients engrafted, with a median time to $\mathrm{ANC}>0.5 \times 10^{9} / 1$ of 10 days. All patients fully engrafted, with a median time to achieve ANC $>0.5 \times 10^{9} / \mathrm{L}$ and PLT $>20 \times 10^{9} / 1$ superimposable to those of other conventional conditioning regimens (10 and 13 days, respectively). The 100-day transplant-related mortality was $0 \%$. After a median follow-up of 30 months (last update June 2012), 32/43 patients (74\%) are in complete remission, whereas $11 / 43$ relapsed and 3/43 died. Five out of 28 NHL patients (17\%), as well as 6/15 (40\%) HD patients relapsed. Disease type (NHL versus HD) and disease status at transplant (chemosensitive vs. chemoresistant) significantly influenced disease-free survival $(p=0.01 ; p=0.007)$. Remarkably, 4/43 (9\%) patients achieved the first complete remission after receiving the high-dose therapy with ASCT. We concluded that the BeEAM regimen is safe and effective for heavily pretreated lymphoma patients, with $74 \%$ of patients being alive and disease-free after a median follow-up of 30 months. Further studies are warranted to confirm these preliminary results. For this reason, we are currently running a new study testing Bendamustine at $200 \mathrm{mg} / \mathrm{m}^{2} /$ day over 2 days in aggressive (DLBC or grade III follicular lymphoma) Bcell lymphoma.

Nieto $\mathrm{Y}$ et $\mathrm{al}^{45}$ developed a new HDT combination of infusional gemcitabine with busulfan/melphalan for lymphoid tumors. Gemcitabine dose was escalated by extending infusions at a fixed rate of $10 \mathrm{mg} / \mathrm{m}^{2} / \mathrm{min}$ in sequential cohorts, in daily 3 - or 2-dose schedules. 
Each dose immediately preceded busulfan or melphalan. 133 patients were enrolled (80HL, $46 \mathrm{NHL}$, 7 MM). Primary refractory disease was present in $45 \%$ of NHL patients, and $50 \%$ of patients were PETpositive at transplant. The 2-dose schedule was better tolerated. Overall response and CR rate were $100 \%$ and $69 \%$ respectively in aggressive B-cell NHL, and 66\% and $66 \%$ in T-cell NHL. After a median of follow up of 24 months, EFS and OS rates are 60 and $89 \%$ respectively (B-NHL), and $70 \%$ and $70 \%$ (T-NHL).

In parallel to novel chemotherapeutic agents, several investigators tested the safety and the efficacy of adding or incorporating radioimmunotherapy in HDT prior to ASCT.

Radioimmunotherapy is a novel type of immunotherapy that uses a linker to combine a monoclonal antibody with a certain specificity linked with a radioimmunoconjugate. The currently available agents used in lymphoma target the CD20 molecule. Two radiolabeled antibodies, iodine-131 tositumomab and yttrium-90 ibritumomab, have been approved by the US Food and Drug Administration (FDA) to treat relapsed lymphoma.

Radiation therapy has been a component of the conditioning regimens used to treat lymphoma in the past. Because lymphomas are highly sensitive to radiation, radioimmunotherapy (RIT) has been used with great success in consolidation therapy and, as a result, either as a single agent or as augmentation of HDT, as part of a conditioning regimen for ASCT. The flexibility of including RIT as part of conditioning therapy also allows it to be combined with RIC to reduce the toxic effects of HDC. In fact, RIT delivers targeted radiation to lymphoma sites protecting other tissues; therefore, it limits toxicity and allows the use of ASCT in older patients or in patients with comorbidities and decreased organ function. This treatment option replaces any concomitant loss of chemotherapy efficacy with a gain in RIT efficacy. The data so far suggest that the use of RIT in the autologous setting can improve clinical outcome with no added toxicity in these patients, whereas similar positive findings have been reported in preliminary studies of RIT combined with RIC and alloSCT in high-risk patients.

Both antibodies have been used in phase I and phase II clinical trials, in conventional standard dose or escalated high dose, to increase the therapeutic effect of high-dose therapy or to substitute TBI, with the aim of reducing relapse rate without adding toxicity to the conditioning regimens. Table $3^{46-55}$ summarizes several trials that have incorporated radioimmunotherapy to the conditioning regimen. While no comparative trials against standard radiation therapy have been done, these phase I-II trials have shown this approach to be safe with low TRM.

The Blood and Marrow Transplant Clinical Trials Network (BMT CTN) conducted a prospective multicenter randomized phase III trial $(0401)^{56}$ comparing high-dose therapy with carmustine, etoposide, cytarabine, and melphalan (BEAM) plus rituximab vs. BEAM plus conventional dose tositumomab (Bexxar) followed by autoHCT in patients with chemotherapy-sensitive relapsed DLBCL.

Table 3 . Radioimmunotherapy in conventional or high dose as part of conditioning regimens for autologous transplantation in lymphoma

\begin{tabular}{|c|c|c|c|c|c|c|}
\hline Study & $\begin{array}{c}\text { Patients } \\
\left(n^{\circ}\right)\end{array}$ & Histology & RIT & Regimen & PFS (\%) & OS (\%) \\
\hline \multicolumn{7}{|l|}{ Standard-dose RIT + Chemotherapy } \\
\hline Vose et al [46] & 23 & Aggressive & ${ }^{131} \mathrm{I}$ & BEAM & $3 y: 39$ & $3 y: 55$ \\
\hline Khouri et al [47] & 26 & Various & ${ }^{90} \mathrm{Y}$ & BEAM & $3 y: 83$ & $3 y: 92$ \\
\hline Vose et al [48] & 40 & DLBCL & ${ }^{131} \mathrm{I}$ & BEAM & $3 y: 70$ & $3 y: 81$ \\
\hline Shimoni et al [49] & 23 & Aggressive & ${ }^{90} \mathrm{Y}$ & BEAM & $3 \mathrm{y}: 52$ & $3 y: 67$ \\
\hline Shimabukuro-Vornhagen et al [50] & 10 & DLBCL and FL & ${ }^{90} \mathrm{Y}$ & BEAM & NR & NR \\
\hline Krishnan et al [51] & 41 & Most DLBCL & ${ }^{90} \mathrm{Y}$ & BEAM & $3 y: 70$ & $2 \mathrm{y}: 89$ \\
\hline Decaudin et al [52] & 77 & Most FL & ${ }^{90} \mathrm{Y}$ & BEAM & $2 \mathrm{y}: 63$ (EFS) & $2 \mathrm{y}: 97$ \\
\hline \multicolumn{7}{|l|}{ High-dose RIT + Chemotherapy } \\
\hline Press et al [53] & 52 & Various & ${ }^{131} \mathrm{I}$ & $\mathrm{Cy}, \mathrm{VP} 16$ & $2 \mathrm{y}: 68$ & $2 \mathrm{y}: 83$ \\
\hline Nademanee et al [54] & 42 & Various & ${ }^{90} \mathrm{Y}$ & $\mathrm{Cy}, \mathrm{VP} 16$ & $4 y: 65$ (DFS) & $4 \mathrm{y}: 81$ \\
\hline Winter et al [55] & 44 & Various & ${ }^{90} \mathrm{Y}$ & BEAM & $3 y: 43$ & $3 y: 60$ \\
\hline
\end{tabular}

Legend. RIT: radioimmunotherapy, BEAM= BCNU-etoposide-cytarabine-melphalan, DLBCL = diffuse large B-cell lymphoma, FL = follicular lymphoma, NR = not reported. 
The Bexxar/BEAM and the R/BEAM regimens produced similar 2-yr PFS and OS for patients with chemosensitive, relapsed DLBCL. No differences in engraftment or other toxicities were apparent other than an increase in mucositis with the Bexxar/BEAM regimen. No significant difference in the risk of MDS or AML was detected with the follow up available (median 25.5 months) at the time of publication.

Despite all the experience and information gathered on this disease there remains no regimen that has demonstrated superiority. Studies published in the Rituximab era appear to show less toxicity then the pioneering works of the 90 's, but no significant improvements in OS rates was demonstrated for patients submitted to HDT/ASCT.

While salvage with R-chemotherapy followed by HDT/ASCT remains a viable option, new strategies have to be taken in account for the remaining patients with relapsed/refractory aggressive lymphomas.

For the time being, allogeneic SCT and, very recently, T-replete haploidentical $\mathrm{SCT}^{57}$ represent the most attractive alternative. For patients who failed a previous ASCT, encouraging results have been seen with allogeneic SCT as a salvage strategy. The European Group for Blood and Marrow Transplantation (EBMT) registry published a retrospective analysis of 101 patients. ${ }^{15}$ Two-third of the patients received a reduced-intensity conditioning (RIC) regimen and $70 \%$ had an identical sibling donor. Outcomes at 3 years were encouraging, with nonrelapse mortality (NRM) rate of $28.2 \%$, a relapse rate of $30 \%$, a PFS rate of $41 \%$, and an OS rate of $53 \%$ Patients with a long remission after autoSCT and with sensitive disease at the time of allogeneic SCT seems to be the best candidates for this approach.

T-Cell Lymphoma. Peripheral T-Cell lymphoma (PTCL) and natural killer/T-cell lymphoma constitute a rare and very heterogeneous group of NHL. In Western countries, they account for $10 \%$ to $15 \%$ of all adult lymphomas. With the exception of anaplastic large-cell lymphoma (ALCL) positive for anaplastic lymphomakinase (ALK), PTCL carries a poor prognosis with low OS and DFS with conventional chemotherapy.

The most frequent T-Cell lymphoma is represented by PTCL not otherwise specified, ALCL and by angioimmunoblastic T-cell lymphoma (AITL).

Five prospective studies incorporating HDT/ASCT as part of first-line therapy have been reported. Corradini et al. $^{58}$ published the results of two prospective phase II trials, investigating the role of high-dose sequential chemotherapy followed by ASCT in 62 patients with PTCL. Conditioning regimen consisted of mitoxantrone and melphalan or carmustine, etoposide, Ara-C and melphalan followed by PBSC autografting. In an intent-to-treat analysis, $74 \%$ completed the whole programme, whereas 16 patients did not undergo ASCT, mainly due to disease progression. At a median follow-up of 76 months, the estimated 12-year OS, DFS and EFS were 34, 55 and $30 \%$, respectively. OS and EFS were significantly better in patients with ALK-positive ALCL, as compared with the remaining PTCL. Multivariate analysis showed that patients obtaining $\mathrm{CR}$ before ASCT had a statistically significant benefit in terms of OS and EFS.

Reimer et. $\mathrm{al}^{59}$ reported the results of a prospective, multicenter study wich included 83 patients. Main subgroups were PTCL not specified $(\mathrm{n}=32)$ and angioimmunoblastic T-cell lymphoma $(\mathrm{n}=27)$. Fiftyfive $(66 \%)$ of the 83 patients received transplantation. The main reason for not receiving ASCT was progressive disease. The treatment regimen consisted of four to six cycles of cyclophosphamide, doxorubicin, vincristine, and prednisone followed by mobilizing therapy with either the dexamethasone, carmustine, melphalan, etoposide, and cytarabine protocol or the etoposide, methylprednisolone, cytarabine, and cisplatin protocol and stem-cell collection. Patients in CR PR underwent myeloablative chemoradiotherapy (fractionated total-body irradiation and high-dose cyclophosphamide) and ASCT. In an intent-to-treat analysis, the overall response rate after myeloablative therapy was $66 \%$ (56\% CR and $8 \% \mathrm{PR})$. The estimated 3-year overall and disease-free survival rates for patients in CR (calculated from CR to the date of relapse) and 3-year progression-free survival rate were $48 \%, 53 \%$, and $36 \%$, respectively.

The Nordic Lymphoma Group (NLG) ${ }^{60}$ conducted a large prospective phase II study in untreated systemic PTCL. Treatment-naive patients with PTCL age 18 to 67 years (median, 57 years) were included. ALKpositive ALCL was excluded. An induction regimen of six cycles of biweekly CHOEP (cyclophosphamide, doxorubicin, vincristine, etoposide, and prednisone) was administered. If in complete or partial remission, patients proceeded to consolidation with HDT/ASCT. 160 patients had histopathologically confirmed PTCL. A total of 115 underwent HDT/ASCT, with 90 in complete remission at 3 months post-transplantation. Early failures occurred in 26\%. Treatment-related mortality was $4 \%$. Consolidated 5-year OS and PFS were $51 \%$ and $44 \%$, respectively. Best results were obtained in ALK-negative ALCL.

The Gel-Tamo Study Group investigator published their experience in 26 patients with PTCL, excluding ALK-positive ALCL ${ }^{61}$. Patients received 3 courses of mega-CHOP (dose-escalated CHOP) and, if the gallium scan was negative, 1 additional course followed by ASCT. Those who remained positive 
Table 4. Prospective series on the use of fronline ASCT in high-risk PTCL

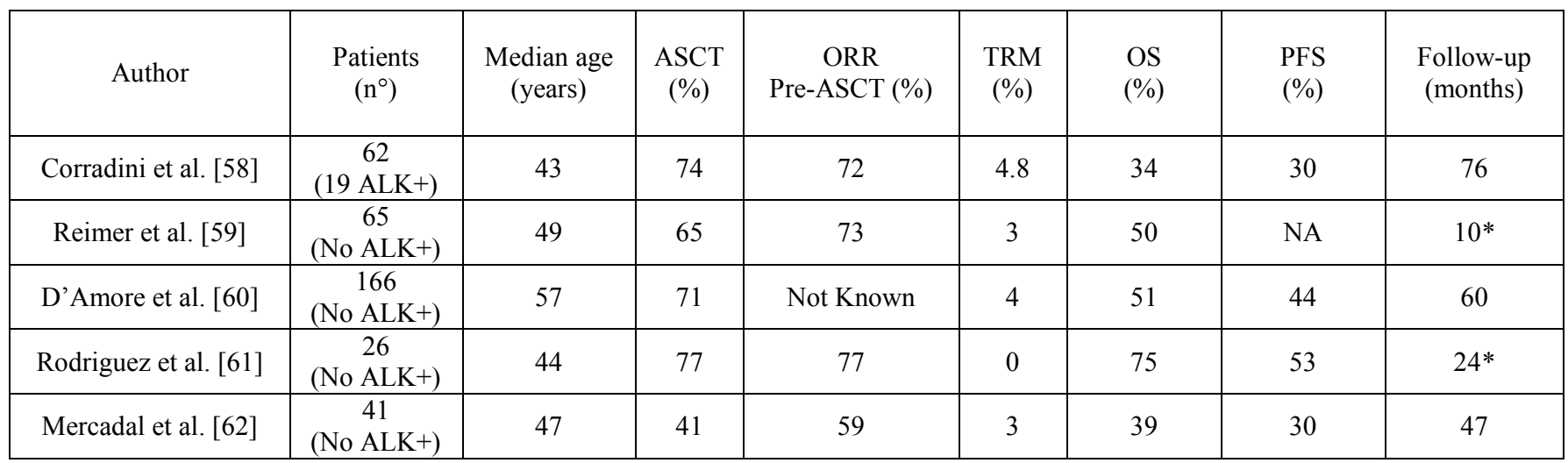

Legend. DLCL: diffuse large cell lymphoma, aaIPI: adjusted-age International Prognostic Index, PFS: progression-free survival, EFS: eventfree survival, OS: overall survival, NS: not significant.

received 2 courses of ifosfamide and etoposide and, if in partial remission (PR) went to ASCT. After ASCT, 19 patients were in CR. Six patients were not transplanted, 5 due to progressive disease and 1 due to lethal toxicity. At two years following transplant, OS and PFS were $73 \%$ and $53 \%$, respectively.

Mercadal et al. ${ }^{62}$ reported the results of a phase II trial in 41 patients with PTCL Induction chemotherapy included high-dose CHOP, alternating with etoposide, cisplatin, cytarabin and prednisone for a total of 6 courses. Responders received ASCT. Only 20 patients achieved complete or partial response, and 17 proceeded to transplant. With a median of follow-up of 3,2 years the PFS and OS rates at 4 years were $30 \%$ and $39 \%$ respectively.

These publications (Table 4) suggest that consolidation of CR1 with ASCT is feasible and safe. However up to one-third of patients may never receive transplant mostly due to progressive disease, thus pointing to the need for better induction regimen. The results suggest improvement in OS and DFS when compared with chemotherapy alone. In the setting of relapsed disease, ASCT has shown results comparable to those achieved in relapsed aggressive B-cell lymphoma. Long-term DFS was reported in $30 \%$ to $50 \%$ of patients, making auto-HCT effective therapy for this indication. In patients with refractory disease the outcome remains poor and other strategies are needed. ${ }^{6-8}$ HTD/ASCT is generally not recommended in this setting because relapse rates have been exceedingly high and long-term survival cannot be expected.

Conclusions. High dose therapy followed by autologous stem cell transplantation (HDT/ASCT) and/or allogeneic stem cell transplantation has still a clear role in the treatment armamentarium of an highly heterogeneous disease known as aggressive lymphomas.
Regarding B-cell lymphomas, the recent incorporation of Rituximab into virtually all first-line therapies of all B-cell lymphomas resulted in a major improvement of conventional therapy. Althoug a consensus is missing, due to the fact that the results of studies incorporating HDT/ASCT in the frontline therapy of aggressive B-cell lymphoma are contradictory, a significant proportion of high risk (high aaIPI) may still benefit from HDT/ASCT, at least in terms of longer disease-free survival.

On the other hand patients with relapsed or refractory B-cell lymphoma are more difficult to salvage at the present time than in the pre-rituximab era. While salvage with R-chemotherapy followed by HDT/ASCT remains a viable option in the Rituximab era, other options should be tried. In fact results from clinical trials of relapsed patients are disappointing, thus novel strategies, which can enhance the antilymphoma effect, at the same time reducing toxicity need to be exploited with the aim of improving the outcome of HDT/ASCT in aggressive NHL. Studies testing novel high-dose strategies prior to ASCT and studies comparing the efficacy of alloSCT and HDT/ASCT are warranted, and some of them are currently on the way.

For patients with T-cell lymphoma, no major progress has been made over the last decade ; phase III studies comparing chemotherapy to novel agents or combining them are ongoing. However, no magic bullet such as Rituximab for B-cell lymphoma seems to stand in the landscape of T-cell lymphomas. In this regard, even if the results of some studies support the use of HDT/ASCT for patients with T-cell lymphoma, showing that a small proportion of patients with T-cell lymphoma may survive several years without disease after HDT/ASCT, we think that allogeneic SCT will play an increasing role for all patients with T-cell lymphoma, including high-risk patients needing firstline therapy. 


\section{References:}

1. Gianni AM, Bregni M, Siena S, et al. High-dose chemotherapy and autologous bone marrow transplantation compared with MACOP$B$ in aggressive B-cell lymphoma. $N$ Engl $J$ Med. 1997;336(18):1290-1297.

http://dx.doi.org/10.1056/NEJM199705013361804 PMid:9113932

2. Santini G, Salvagno L, Leoni P, et al. VACOP-B versus VACOP-B plus autologous bone marrow transplantation for advanced diffuse non-Hodgkin's lymphoma: results of a prospective randomized trial by the non-Hodgkin's Lymphoma Cooperative Study Group. J Clin Oncol. 1998:16(8):2796-2802. PMid:9704732

3. Gisselbrecht C, Lepage E, Molina T, et al. Shortened first-line high-dose chemotherapy for patients with poor-porgnosis aggressive lymphoma. J Clin Oncol. 2002;20(10):2472-2479. http://dx.doi.org/10.1200/JCO.2002.02.125 PMid:12011124

4. Kaiser U, Uebelacker 1 , Abel U, et al. Randomized study to evaluate the use of high-dose therapy as part of primary treatment for aggressive lymphoma. J Clin Oncol. 2002;20(22):4413-4419. PMid:12431962

5. Martelli M, Gherlinzoni F, De Renzo A, et al. Early autologous stem-cell transplantation versus conventional chemotherapy as front-line therapy in high-risk, aggressive non-Hodgkin's lymphoma: an italian muticenter randomized trial. J Clin Oncol. 2003;21(7):1255-1262. http://dx.doi.org/10.1200/JCO.2003.01.117 PMid:12663712

6. Olivieri A, Santini G, Patti C, et al. Upfront high-dose sequential therapy (HDS) versus VACOP-B with or without HDS in aggressive non-Hodgkin's lymphoma: long-term results by the NHLCSG. Ann Oncol. 2005;16(12):1941-1948. http://dx.doi.org/10.1093/annonc/mdi399 PMid:16157621

7. Vitolo U, Liberati AM; Cabras MG, et al. High dose sequential chemotherapy with autologous transplantation versus dose-dense chemotherapy MegaCEOP as first line treatment in poor-prognosis diffuse large cell lymphoma: an Intergruppo Italiano Limfomi randomized trial. Haematologica 2005;90(6):793-801. PMid:15951292

8. Betticher DC, Martinelli G, Radford JA, et al. Sequential high dose chemotherapy as initial treatment for aggressive sub-type of nonHodgkin lymphoma: results of the international randomized phase III trial (MISTRAL). Ann Oncol. 2006;17(10):1546-1552. http://dx.doi.org/10.1093/annonc/mdl153 PMid:16888080

9. Haioun C, Lepage E, Gisselbrecht C, et al. Survival benefit of high-dose therapy in poor-risk aggressive non-Hodgkin's lymphoma: final analysis of the prospective LNH87-2 protocol - a groupe d'Etude des Lymphomes de 1'Adulte study. J Clin Oncol. 2000;18(16):3025-3030. PMid:10944137

10. Baldisserra RC, Nucci M, Vigorito AC, et al. Frontline therapy with early intensification and autologous stem cell transplantation versus conventional chemotherapy in unselected high-risk, aggressive non-Hodgkin's lymphoma patients: a prospective randomized GEMOH report. Acta Haematol. 2006;115(1-2):15-21. PMid:16424644

11. Klui-Nelemans HC, Zagonel V, Anastasopoulou A, et al. Standard chemotherapy with or without high-dose chemotherapy for aggressive non-Hodgkin's lymphoma: randomized phase III E EORTC study. J Natl Cancer Inst. 2001;93(1):22-30. PMid:11136838

12. Oliansky DM, Czuczman M, Fisher RI, et al. The role of cytotoxic therapy with hematopoietic stem cell transplantation in the treatment of diffuse large B cell lymphoma: update of the 2001 evidence-based review. Biol Blood Marrow Transplat. 2011;17(1):20-47. http://dx.doi.org/10.1016/j.bbmt.2010.07.008 PMid:20656046

13. Greb A, Bohlius J, Schiefer D, et al. High-dose chemotherapy with autologous stem cell transplantation in the first line treatment of aggressive non-Hodgkin lymphoma (NHL) in adults. Cochrane Database Syst Rev. 2008 CD004024. PMid:18254036

14. Tarella C, Zanni M, Di Nicola M, et al. Prolonged survival in poorrisk diffuse large B-cell Lymphoma following front-line treatment with rituximab-supplemented, early-intensified chemotherapy with multiple autologous hematopoietic stem cell support: a multicenter study by GITIL (Gruppo Italiano Terapie Innovative nei Linfomi). Leukemia $\quad 2007 ; \quad 21: \quad 1802-1811$. http://dx.doi.org/10.1038/sj.leu.2404781 PMid:17554382

15. Vitolo U, Chiappella E, Angelucci E, et al. Dose-dense and highdose chemotherapy plus rituximab with autologous stem cell transplantation for primary treatment of diffuse large B-cell lymphoma with a poor prognosis: a phase II multicenter study. Haematologica 2009; 240 94 http://dx.doi.org/10.3324/haematol.2009.007005 PMid:19586937 PMCid:2738717

16. Fitoussi O, Belhadj K, Mounier N, et al. Survival impact of rituximab combined with ACVBP and upfront consolidative autotransplantation in high risk diffuse large B-cell lymphoma for GELA. Haematologica 2011; 96: 1136-1143. http://dx.doi.org/10.3324/haematol.2010.038109 PMid:21546499 PMCid:3148907

17. Stiff PJ, Unger JM, Cook J, et al. Randomized phase III U.S./Canadian intergroup trial (Swog S9704) comparing CHOP (+/-) R for eight cycles to CHOP (+/-) R for six cycles followed by autotransplantation for patients with high-intermediate $(\mathrm{H}$-int) or high IPI grade diffuse aggressive non-Hodgkin lymphoma (NHL). J Clin Oncol. 2011; 29: 8001.

18. Vitolo U, Chiappella A, Brusamolino E, et al. A randomized multicentre phase III study for first-line treatment of young patients with high risk (aaIPI 2-3) diffuse large B-cell lymphoma (DLBCL): rituximab (R) plus dose-dense chemotherapy CHOP14/MegaCHOP14 with or without intensified high-dose chemotherapy (HDC) and autologous stem cell transplantation (ASCT). Results of DLCL04 trial of Italian Lymphoma Foundation (FIL). Ann Oncol 2011 (suppl 4); 22: 072.

19. Schmitz N, Nickelsen M, Ziepert M, et al. Conventional chemoimmunotherapy (R-CHOEP)-14 or high-dose therapy (RMega-CHOEP) for young, high-risk patients with aggressive B-cell lymphoma: final results of the randomized Mega-CHOEP trial of the German High-Grade Non-Hodgkin Lymphoma Study Group (DSHNHL). J Clin Oncol. 2011; 29: 8002.

20. Le Gouill S, Milpied NJ, Lamy T, et al. First-line Rituximab (R) high-dose therapy (R-HDT) versus R-CHOP 14 for young adults with diffuse large B-Cell lymphoma: Preliminary results of the GOELAMS 075 prospective multicenter randomized trial. J Clin Oncol. 2011; 29: 8003.

21. Philip T, Guglielmi C, Hagenbeek A, et al. Autologous bone marrow transplantation as compared with salvage chemotherapy in relapses of chemotherapy sensitive non Hodgkin's lymphoma. N Engl J Med. 1995; 333(23):1540-5. http://dx.doi.org/10.1056/NEJM199512073332305 PMid:7477169

22. Gisselbrecht C, Glass B, Mounier N, et al. Salvage regimens with autologous transplantation for relapsed large B-cell lymphoma in the Rituximab era. J Clin Oncol. 2010; 28(27):4184-4187. http://dx.doi.org/10.1200/JCO.2010.28.1618 PMid:20660832

23. Gisselbrecht C, Glass B, Fournier M, et al. Salvage regimen with autologous stem cell transplantation with or without rituximab maintenance for relapsed diffuse large B-cell lymphoma (DLBCL) : CORAL final report. Ann Oncol 2011 (Suppl 4); 22: 075.

24. Pedersen-Bjergaard J, Andersen MK, Christiansen DH. Therapyrelated acute myeloid leukemia and myelodysplasia after high-dose chemotherapy and autologous stem cell transplantation. Blood. 2000; 95(11):3273-3279. PMid:10828005

25. Fernandez HF, Escalon MP, Pereira D, Lazarus HM. Autotransplant conditioning regimens for aggresive lymhoma : are we on the right road? Bone Marrow Transplant 2007; 40:505-513. http://dx.doi.org/10.1038/sj.bmt.1705744 PMid:17589535

26. van Besien $K$, Tabocoff J, Rodriguez M, et al. High-dose chemotherapy with BEAC regimen and autologous bone marrow transplantation for intermediate grade and immunoblastic lymphoma: durable complete remissions, but a high rate of regimen related toxicity. Bone Marrow Transplant. 1995;15:549555. PMid:7655380

27. Fernandez HF, Escalon MP, Pereira D, Lazarus HM. Autotransplant conditioning regimens for aggressive lymphoma: 
are we on the right road? Bone Marrow Transplant 2007; 40: 505513.

28. Caballero MD, Rubio V, Rifon J, et al. BEAM chemotherapy followed by autologous stem cell support in lymphoma patients: analysis of efficacy, toxicity and prognostic factors. Bone Marrow Transplant 1997; 20: 451-458.

29. Weaver $\mathrm{CH}$, Petersen FB, Appelbaum FR et al. High-dose fractionated total- body irradiation, etoposide, and cyclophosphamide followed by autologous stem-cell support in patients with malignant lymphoma. J Clin Oncol. 1994;12:2559 2566.

30. Salar A, Sierra J, Gandarillas M, et al. GEL/TAMO Spanish Cooperative Group. Autologous stem cell transplantation for clinically aggressive non-Hodgkin's lymphoma: the role of preparative regimens. Bone Marrow Transplant.2001; 27: 405-412.

31. Jo JC, Kang BW, Jang G, et al. BEAC or BEAM high-dose chemotherapy followed by autologous stem cell transplantation in non-Hodgkin's lymphoma patients: comparative analysis of efficacy and toxicity. Ann Hematol. 2008; 87(1):43-8. http://dx.doi.org/10.1007/s00277-007-0360-0 PMid:17710401

32. Gisselbrecht C, Glass B, Mounier N, et al. Salvage regimens with autologous transplantation for relapsed large B-cell lymphoma in the Rituximab era. J Clin Oncol. 2010; 28(27):4184-4187. http://dx.doi.org/10.1200/JCO.2010.28.1618 PMid:20660832

33. Kewalramani T, Zelenetz AD, Nimer SD. Rituximab and ICE as second-line therapy before autologous stem cell transplantation for relapsed primary refractory diffuse large B-cell lymphoma. Blood. 2004; 103:3684-3688. http://dx.doi.org/10.1182/blood-2003-113911 PMid:14739217

34. Oliansky DM, Czuczman M, Fisher RI, et al. The role of cytotoxic therapy with hematopoietic stem cell transplantation in the treatment of diffuse large B cell lymphoma: update of the 2001 evidence-based review. Biol Blood Marrow Transplant. 2011;17(1):20-47. $\quad$ http://dx.doi.org/10.1016/j.bbmt.2010.07.008 PMid:20656046

35. Caballero MD, Rubio V, Rifon J et al. BEAM chemotherapy followed by autologous stem cell support in lymphoma patients: analysis of efficacy, toxicity and prognostic factors. Bone Marrow Transplant. 1997; 20: 451-458. http://dx.doi.org/10.1038/sj.bmt.1700913 PMid:9313877

36. de Magalhaes-Silverman M, Lister J, Rybka W, et al. Busulfan and cyclophosphamide (BU/CY2) as preparative regimen for patients with lymphoma. Bone Marrow Transplant. 1997; 19: 777-781. http://dx.doi.org/10.1038/sj.bmt.1700733 PMid:9134168

37. Fernandez HF. The use of intravenous busulfan and cyclophosphamide as a conditioning regimen for Non Hodgkin's Lymphoma. ASBMT/CIBMTR Tandem Meetings. Honolulu, HI, 2006.

38. Hanel M, Kroger N, Sonnenberg S, et al. Busulfanm cyclophosphamide and etoposide as high dose conditioning regimen in patients with malignant lymphoma. Ann Hematol 2002; 81: 96-102. $\quad$ http://dx.doi.org/10.1007/s00277-001-0413-8 PMid:11907790

39. Schiffman KS, Besinger WI, Appelbaum FR, et al. Phase II study of high-dose busulfan, melphalan and thiotepa with autologous peripheral blood stem cell support in patients with malignant disease. Bone Marrow Transplant. 1996; 17: 943-950. PMid:8807098

40. Stein RS, Greer JP, Goodman S, et al. Intensified preparative regimens and autologous transplantation in refractory or relapsed intermediate grade non Hodgkin's lymphomas. Bone Marrow Transplant. 2000; 25: 257-262 http://dx.doi.org/10.1038/sj.bmt.1702132 PMid:10673696

41. Stiff PJ, Dahlberg S, Forman SJ, et al. Autologous bone marrow transplantation for patients with relapsed or refractory diffuse aggressive non-Hodgkin's lymphoma: value of augmented preparative regimens - Southwest Oncology Group trial. J Clin Oncol. 1998; 16: 48-55 PMid:9440722

42. Wadhwa PD, Fu P, Koc ON, et al. High-dose carmustine, etoposide, and cisplatin for autologous stem cell transplantation with or without involved-field radiation for relapsed/refractory lymphoma: an effective regimen with low morbidity and mortality. Biol Blood Marrow Transplant. 2005; 11: 13-22 http://dx.doi.org/10.1016/j.bbmt.2004.09.003 PMid:15625540

43. Kim JG, Sohn SK, Chae YS, et al. Multicenter study of intravenous busulfan, cyclophosphamide, and etoposide (i.v. Bu/Cy/E) as conditioning regimen for autologous stem cell transplantation in patients with non-Hodgkin's lymphoma. Bone Marrow Transplant 2007; 40: 919-24 http://dx.doi.org/10.1038/sj.bmt.1705841 PMid:17846602

44. Visani G, Malerba L, Stefani P.M, et al. BeEAM (Bendamustine, Etoposide, Cytarabine, Melphalan) prior to autologous stem cell transplant is safe and effective for resistant/relapsed lymphoma patients. Blood 2011; 118: 3419-3425 http://dx.doi.org/10.1182/blood-2011-04-351924 PMid:21816830

45. Nieto Y, Thall B, Valdez B, et al. High dose infusional gemcitabine combined with busulfan and melphalan with autologous stem-cell transplant in patients with refractory lymphoid malignancies. Biol Blood Marrow Transplant 2012 May 27 (epub ahead of print) http://dx.doi.org/10.1016/j.bbmt.2012.05.011 PMid:22643322

46. Vose JM, Bierman PJ, Enke C, et al. Phase I trial of iodine-131 tositumumab with high-dose chemotherapy and autologous stemcell transplantation for relapsed non-Hodgkin's lymphoma. J Clin Oncol. 2005; 23: 461-467 http://dx.doi.org/10.1200/JCO.2005.05.117 PMid:15534357

47. Khouri IF, Saliba RM, Hosing C, et al. Efficacy and safety of yttrium 90 (90Y) ibritumumab tiuxetan in autologous and nonmyeloablative stem cell transplantation (NST) for relapsed non Hodgkins lymphoma (NHL). Blood (ASH Annual Meeting Anstracts). 2006; 108: 315 .

48. Vose J, Bierman P, Bociek G, et al. Radioimmunotherapy with 131-I tositumumab enhanced survival in good prognosis relapsed and high-risk diffuse large B-cell lymphoma (DLBCL) patients receiving high-dose chemotherapy and autologous stem cell transplantation. J Clin Oncol. (ASCO Annual Meeting Proceedings Part I). 2007; 25 (18S June 20 suppl):8013.

49. Shimoni A, Zwas ST, Oksman Y, et al. Yttrium-90-ibritumumab tiuxetan (Zevalin) combined with high-dose BEAM chemotherapy and autologous stem cell transplantation for chemo-refractory aggressive non-Hodgkin's lymphoma. Exp Hematol. 2007; 35: 534-540. $\quad$ http://dx.doi.org/10.1016/j.exphem.2007.01.043 PMid: 17379063

50. Shimabukuro-Vornhagen A, Josting A, Hubel K. Yttrium-90 ibritumumab tiuxetan combined with high-dose BEAM chemotherapy and autologous stem cell transplantation for relapsed/refractory B-cell non Hodgkins lymphoma. J Clin Oncol.2008; 26:8615.

51. Krishnan A, Nademanee A, Fung HC, et al. Phase II trial of a transplantation regimen of yttrium-90-ibritumomab tiuxetan and high-dose chemotherapy in patients with non-Hodgkin's lymphoma. J Clin Oncol. 2008; 26:90-95. http://dx.doi.org/10.1200/JCO.2007.11.9248 PMid:18025438

52. Decaudin D, Mounier N, Tilly H, et al. (90)Y ibritumumab tiuxetan (Zevalin) combined with BEAM (Z-BEAM) conditioning regimen plus autologous stem cell transplantation in relapsed or refractory low-grade CD20-positive B-cell lymphoma: a GELA phase II prospective study. Clin Lymphoma Myeloma Leuk. 2011; 11:212-218 $\quad$ http://dx.doi.org/10.1016/j.clml.2011.03.007 PMid:21575926

53. Press OW, Eary JF, Gooley T, et al. A phase I/II trial of iodine131-tositumumab (anti CD20), etoposide, cyclophosphamide, and autologous stem cell transplantation for relapsed B-cell lymphomas. Blood 2000; 96: 2934-2942. PMid:11049969

54. Nademanee A, Forman S, Molina A, et al. A phase $1 / 2$ trial of high-dose yttrium-90-ibritumumab tiuxetan in cobinationwith highdose etoposide and cyclophosphamide followed by autologous stem-cell transplantation in patients with poor-risk or relapsed nonHodgkin lymphoma. Blood. 2005; 106:2896-2902. http://dx.doi.org/10.1182/blood-2005-03-1310 PMid:16002426 PMCid:1895300

55. Winter JN, Inwards DJ, Spies S, et al., Yttrium-90 ibritumumab tiuxetan doses calculated to deliver up to $15 \mathrm{~Gy}$ to critical organs may be safely combined with high-dose BEAM and autologous transplantation in relapsed or refractory B-cell non-Hodgkin's lymphomas. J Clin Oncol. 2009; 27: 1653-1659. http://dx.doi.org/10.1200/JCO.2008.19.2245 PMid:19255322 PMCid:2668971

56. Vose JM, Carte SL, Burns LJ, et al. Randomized Phase III T rial of 131iodine-Tositumomab (Bexxar)/Carmustine, Etoposide, Cytarabine, Melphalan (BEAM) Vs. Rituximab/BEAM and Autologous Stem Cell Transplantation for Relapsed Diffuse Large 
B-Cell Lymphoma (DLBCL): No Difference in Progression-Free (PFS) or Overall Survival (OS) Blood (ASH Annual Meeting Abstracts) 2011; 118: 661.

57. Luznik L, O'Donnel PV, Symons HJ, et al. HLA-haploidentical bone marrow transplantation for hematologic malignancies using nonmyeloablative conditioning and high-dose, posttransplantation cyclophosphamide Biol Blood Marrow Transplant. 2008 Jun;14(6):641-50. PMid:18489989 PMCid:2633246

58. Corradini P, Tarella C, et al. Long-term follow-up of patients with peripheral T-Cell lymphomas treated up-front with high-dose chemotherapy followed by autologous stem cell transplantation. Leukemia 2006; 20: 1533-1538. http://dx.doi.org/10.1038/sj.leu.2404306 PMid:16871285

59. Reimer P, Rudiger T, et al. Autologous stem-cell transplantaion as first-line therapy in peripheral T-cell lymphomas: results of a prospective multicenter study. J Clin Oncol 2009; 27: 106-13.
http://dx.doi.org/10.1200/JCO.2008.17.4870 PMid:19029417

60. D'Amore F, Relander T, et al. Up-Front Autologous Stem-Cell Transplantation in Peripheral T-Cell Lymphoma: NLG-T-01. J
Clin
Oncol
2012
30 :
$3093-9$

http://dx.doi.org/10.1200/JCO.2011.40.2719 PMid:22851556

61. Rodriguez J, Conde E, et al. Frontline autologous stem cell transplantation in high-risk peripheral T-cell lymphoma: a prospective study from the Gel-Tamo Study Group. Eur J Haematol 2007; 79: 32-38. http://dx.doi.org/10.1111/j.16000609.2007.00856.x PMid: 17598836

62. Mercadal S, Briones J, et al. Intensive chemotherapy (high-dose CHOP/ESHAP regimen) followed by autologous stem-cell transplantation in previously untreated patients with peripheral Tcell lymphoma. Ann Oncol 2008; 19: 958-63. http://dx.doi.org/10.1093/annonc/mdn022 2 PMid:18303032 